\title{
Pearly penile papules
}

\section{Andreas Körber MD, Joachim Dissemond MD}

Previously published at www.cmaj.ca

A 23-year-old man was referred to us with a 4-year history of flesh-coloured, spiny papules around the coronal rim of his glans penis (Figure 1). The papules were 1-2 $\mathrm{mm}$ in diameter. The patient felt stigmatized by their appearance. A diagnosis of pearly penile papules (also known as PPP) was made.

Pearly penile papules commonly develop after puberty. The prevalence of this condition is estimated to be $14 \%-48 \%$, and the incidence is higher among black people and uncircumcised men. ${ }^{1,2}$ Many terms have been used to describe pearly penile papules, including Tyson glands, hirsutoid papillomas, papilla in the corona glandis, hirsutis papillary corona of the penis, corona capilliti and pink pearly papules.

The papules are smooth, measure $1-4 \mathrm{~mm}$ in diameter and are asymptomatic. Commonly, they occur in a single or double row on the corona of the glans. Structurally, they are related to acral angiofibromas. Pearly penile papules need to be differentiated from condylomata accuminata and lichen nitidus. Compared with condylomata accuminata, pearly penile papules are more uniform, are localized strictly at the glans penis or the sulcus coronarius and do not have a cauliflower-like surface. Lichen nitidus papules are flesh-coloured and flat-topped and they tend to occur on the shaft of the penis.

When diagnosis is uncertain, a biopsy may be performed to rule out other conditions. ${ }^{1}$ Several modes of therapy are used for treating pearly penile papules, including cryotherapy, electrodesiccation, podophyllin, curettage and carbon dioxide laser ablation. Ablation using intermittent- or continous-mode carbon dioxide laser is reported to have the best outcome cosmetically. Treatment should be reserved for patients who are highly distressed by the appearance of this very common and benign entity. ${ }^{2}$

\section{REFERENCES}

1. Hogewoning JA, Bleeker MC, van den Brule AJ, et al. Pearly penile papules: Still no reason for uneasiness. J Am Acad Dermatol 2003;49:50-4.

$\varpi$ 2. Agrawal SK, Bhattacharya SN, Singh N. Pearly penile papules: a review. Int J Dermatol 2004:43:199-201.

From the Department of Dermatology, Faculty of Medicine, University of Duisburg-Essen, Essen, Germany

Cite as CMAJ 2009. DOI:10.1503/cmaj.081861

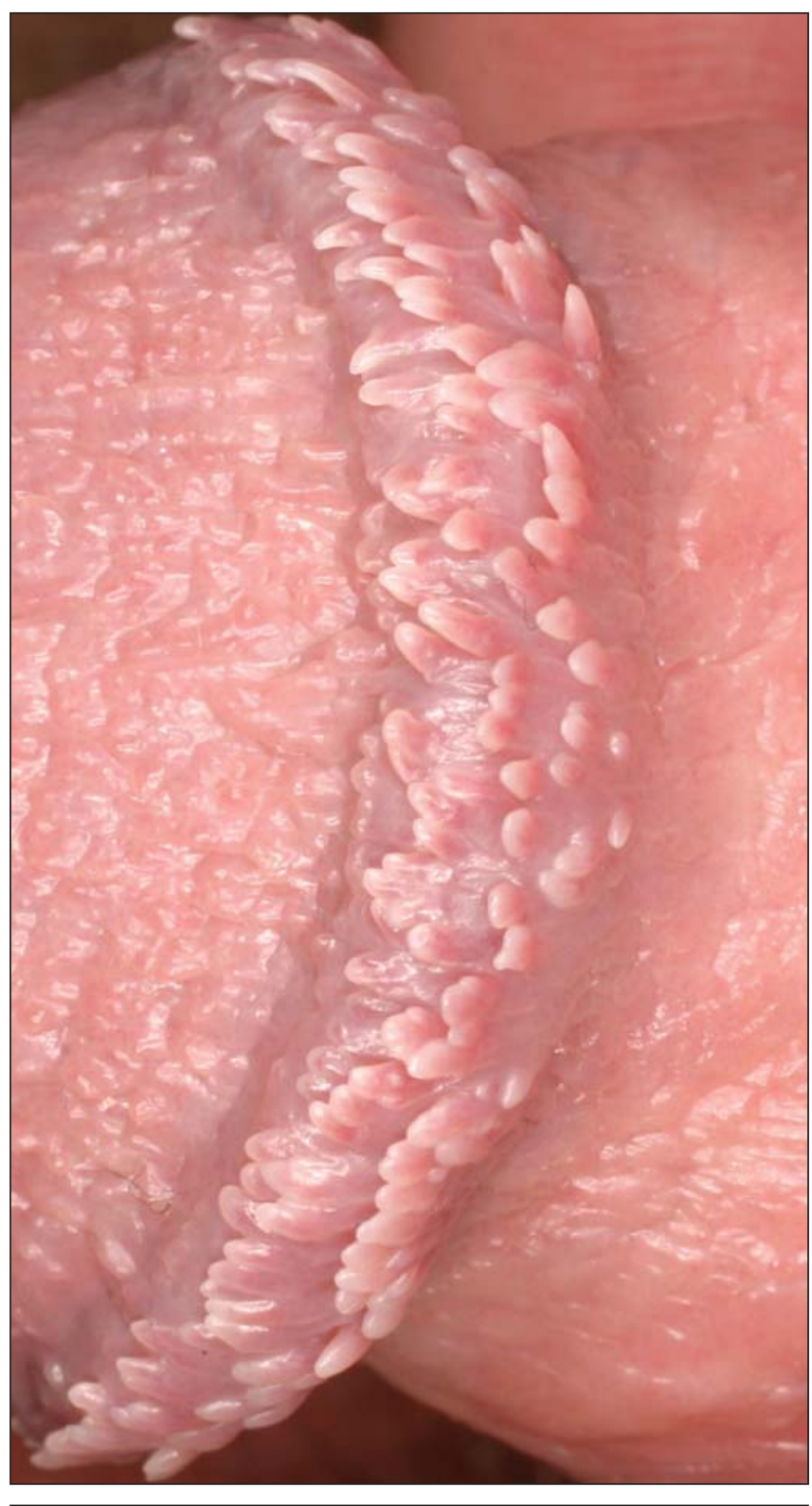

Figure 1: Photograph of the glans penis of a 23-year-old man, showing multiple flesh-coloured papules of 1-2 $\mathrm{mm}$ in diameter at the sulcus coronarius. 